\title{
Rural-Urban Differences in Risk Factors for Motor Vehicle Fatalities
}

\author{
Carrie Henning-Smith* and Katy B. Kozhimannil
}

\begin{abstract}
Purpose: To examine rural-urban differences in motor vehicle fatality (MVF) risk factors. Methods: We used 2017 County Health Rankings data to run stratified regression models to estimate countylevel correlates of motor vehicle fatalities (MVFs) by rural and urban location.

Results: Rural counties have higher rates of MVFs than urban counties (22 vs. 14 per 100,000, p<0.001). Physical inactivity and uninsurance were associated with higher rates of MVFs, as was having a more racially or ethnically concentrated population and larger percentages of younger or older adults.

Conclusion: Interventions to reduce MVFs should take geographic location and population composition into account.
\end{abstract}

Keywords: motor vehicle fatalities; rural; urban

\section{Introduction}

Motor vehicle fatalities (MVFs), combined with other types of unintentional injuries, are one of the five leading causes of death in the United States, and the leading cause of death among people of ages 1-44 years. ${ }^{1,2}$ Mortality rates from all five leading causes of death, including MVFs, are higher in rural areas than in urban areas. $^{1,2}$ Furthermore, although the overall rate of MVFs is declining, it remains higher in rural areas than in urban areas. $^{3}$ In addition to geography, MVF rates are also associated with sociodemographic characteristics, including race, ethnicity, age, and gender, which differ between rural and urban communities. ${ }^{2,4-6}$ For example, MVF rates are highest among American Indian/ Alaskan Native populations, compared with all other racial and ethnic groups, ${ }^{2}$ men are more likely to die from motor vehicle crashes than women, ${ }^{7}$ and individuals under the age of 20 years and over the age of 69 years are more likely than those in middle age to have MVFs. ${ }^{7}$ Above and beyond individual characteristics, state policy context also matters for MVF rates; for example, states with stricter seat belt and texting-whiledriving laws have lower rates of MVF. ${ }^{6,8}$ Less is known about whether rural-urban differences in MVFs persist after adjusting for population characteristics and state context and whether sociodemographic risk factors for MVFs differ by rural-urban location. This study addresses that gap and its results will be useful in tailoring interventions by geographic location to reduce MVFs risk.

\section{Methods}

Data for this study come from the 2017 County Health Rankings, a compilation of county-level data produced by the University of Wisconsin with funding from the Robert Wood Johnson Foundation. We included all 2,709 counties for which there were complete data on the MVFs rate ( $86 \%$ of counties) and compared the MVFs rate by rural-urban location. We defined rural and urban location using Federal Office of Management 
and Budget definitions, categorizing all micropolitan and noncore counties as "rural" and all metropolitan counties as "urban." We used ordinary least squares regression to model the association between rural-urban location and the MVFs rate, adjusting for various county-level sociodemographic characteristics. We stratified the analysis, running regression models separately for rural and urban location, to see whether risk factors for MVFs differed by geographic location. In all models, we included a fixed effect for state, as differences in state policies are associated with differences in MVF rates. ${ }^{6,8,9}$

\section{Results}

For every 100,000 people, rural counties experienced eight more deaths by MVFs than urban counties per year (22 vs. $14, p<0.001$ ); Table 1 . Based on current population, this difference amounts to nearly 4000 additional lives lost per year in rural counties.

After adjusting for county-level characteristics, including health behaviors, socioeconomic characteristics, and demographic composition, rurality continued to be associated with a higher rate of MVFs, amounting to three additional deaths per 100,000 $(p<0.001)$; Table 1. Higher rates of physical inactivity and uninsurance were associated with higher county-level rates of MVFs, as was having a larger percentage of the population $<18$ years old or $>64$ years old. Having a more racially or ethnically concentrated population was associated with higher rates of MVFs, with rates being especially high for counties with a higher percentage of American Indian/Alaskan Native individuals $(b=61.97, p<0.001)$. Having more adults with some college and a greater proportion of females in the county was both associated with lower rates of MVFs. Contrary to our hypotheses, having higher rates of both excessive drinking and insufficient sleep was both associated with lower rates of MVFs in U.S. counties.

In stratified analyses by geography, many, but not all, of the risk factors for increased rates of MVFs remained consistent. Exceptions included adult obesity, which was associated with higher rates of MVFs in urban $(p<0.05)$ but not rural counties. The percentage of adults with some college had a significant negative relationship with MVFs for urban $(p<0.001)$ but

Table 1. Correlates of Motor Vehicle Fatalities by Rural-Urban Location

\begin{tabular}{|c|c|c|c|c|c|c|c|c|c|}
\hline \multirow{4}{*}{$\begin{array}{l}\text { Observations (counties), } \mathrm{n} \\
\text { Motor vehicle fatality rate (per 100,000) }\end{array}$} & \multicolumn{3}{|c|}{ Full sample } & \multicolumn{3}{|c|}{ Urban only } & \multicolumn{3}{|c|}{ Rural only } \\
\hline & \multicolumn{3}{|c|}{2709} & \multicolumn{3}{|c|}{1124} & \multicolumn{3}{|c|}{1585} \\
\hline & \multicolumn{3}{|c|}{18.80} & \multicolumn{3}{|c|}{14.03} & \multicolumn{3}{|c|}{22.18} \\
\hline & Coefficient & $S E$ & $\mathrm{p}$ value & Coefficient & $S E$ & p value & Coefficient & $S E$ & p value \\
\hline Rural (ref: Urban) & 2.86 & 0.32 & 0.000 & & & & & & \\
\hline \multicolumn{10}{|l|}{ Health behaviors } \\
\hline Adult smoking & 12.42 & 8.17 & 0.129 & -9.90 & 8.31 & 0.233 & 21.17 & 12.44 & 0.089 \\
\hline Excessive drinking & -28.47 & 6.57 & 0.000 & -15.17 & 6.08 & 0.013 & -37.66 & 10.86 & 0.001 \\
\hline Insufficient sleep & -35.89 & 5.98 & 0.000 & -40.99 & 5.59 & 0.000 & -29.11 & 9.88 & 0.003 \\
\hline Physical inactivity & 43.36 & 4.59 & 0.000 & 40.60 & 4.91 & 0.000 & 41.97 & 6.89 & 0.000 \\
\hline Adult obesity & 1.97 & 4.89 & 0.687 & 10.97 & 5.05 & 0.030 & -2.47 & 7.40 & 0.738 \\
\hline \multicolumn{10}{|l|}{ Socioeconomic characteristics } \\
\hline Uninsured & 31.28 & 4.39 & 0.000 & 29.67 & 4.71 & 0.000 & 31.84 & 6.49 & 0.000 \\
\hline Unemployment rate & -20.19 & 10.34 & 0.051 & 2.04 & 11.25 & 0.856 & -27.59 & 15.54 & 0.076 \\
\hline Adults with some college & -6.52 & 2.20 & 0.003 & -18.63 & 2.33 & 0.000 & -0.07 & 3.36 & 0.983 \\
\hline Child poverty rate & 2.42 & 3.49 & 0.489 & -5.13 & 3.81 & 0.179 & 4.89 & 5.15 & 0.343 \\
\hline Food insecurity & 4.31 & 7.05 & 0.541 & 10.80 & 6.76 & 0.110 & 3.30 & 11.41 & 0.773 \\
\hline \multicolumn{10}{|l|}{ Demographic composition } \\
\hline Percentage under 18 & 55.41 & 7.20 & 0.000 & 10.97 & 7.10 & 0.122 & 81.13 & 11.26 & 0.000 \\
\hline Percentage 65 and older & 42.65 & 6.23 & 0.000 & 12.22 & 6.09 & 0.045 & 58.19 & 9.81 & 0.000 \\
\hline Percentage black & 38.46 & 10.29 & 0.000 & 11.79 & 10.65 & 0.268 & 43.96 & 17.95 & 0.014 \\
\hline Percentage Hispanic & 28.61 & 10.11 & 0.005 & -0.82 & 10.39 & 0.937 & 35.43 & 17.55 & 0.044 \\
\hline Percentage American Indian/Alaskan Native & 61.97 & 10.73 & 0.000 & 35.62 & 11.88 & 0.003 & 63.84 & 18.61 & 0.001 \\
\hline Percentage Asian & 23.54 & 14.45 & 0.103 & -1.94 & 13.69 & 0.887 & 11.06 & 36.56 & 0.762 \\
\hline Percentage white & 33.00 & 10.42 & 0.002 & 8.85 & 10.77 & 0.411 & 37.48 & 18.15 & 0.039 \\
\hline Percentage female & -49.53 & 8.28 & 0.000 & -34.15 & 9.33 & 0.000 & -63.18 & 12.37 & 0.000 \\
\hline Adjusted $r^{2}$ & 0.51 & & & 0.60 & & & 0.35 & & \\
\hline
\end{tabular}

Source: Authors' analysis of 2017 County Health Rankings. 
not rural counties $(p=0.983)$. Meanwhile, having a higher percentage of younger adults was associated with higher rates of MVFs in rural counties $(p<0.001)$ but not urban $(p=0.122)$. In general, the association between age, gender, racial, and ethnic composition and MVF rates was consistently larger and more significant in rural counties. The adjusted $\mathrm{r}^{2}$ for the three models indicated that more of the variance in MVF rates was explained in the full model (adjusted $r^{2}=0.51$ ) and urban subgroup model (adjusted $r^{2}=0.60$ ), compared with the rural subgroup model (adjusted $r^{2}=0.35$ ), suggesting that other unobserved factors play more significant roles in predicting MVF rates in rural counties.

\section{Discussion}

We found higher rates of MVFs among rural counties, confirming other research on this topic. ${ }^{1} \mathrm{We}$ also found that those differences cannot be entirely explained by differences in health behaviors or sociodemographic composition of the population. However, our analysis was limited by available data, and there are likely several unobserved factors that contribute to differences in MVFs by geography. For instance, rural drivers tend to drive at higher speeds, are less likely to use seat belts, and are more likely to have older vehicles with fewer safety features, such as airbags. ${ }^{10,11}$ Furthermore, rural and urban areas differ in their perceptions of transportation challenges and rural residents are less likely than urban residents to limit their driving, even if they have a medical condition that makes it difficult to drive safely. ${ }^{12}$ This may be due to more limited availability of viable transportation alternatives, such as public transportation or affordable taxi services for rural residents.

Higher death rates in rural areas have caused alarm among public health practitioners and deserve urgent attention. MVFs are one of the leading causes of potentially preventable deaths in rural counties nationally and require broad policy support. Such policy interventions must go beyond state laws about seat belts, texting, and similar safety issues, ${ }^{6,8,9}$ all of which are important, but are unable to prevent all MVFs and to eliminate rural-urban disparities in MVF rates. Reducing MVF rates in rural counties will require a multifaceted approach, including addressing rural transportation infrastructure, access to healthcare, and emergency response capability. ${ }^{2}$

MVF rates also differ by population composition in rural and urban communities, and efforts to re- duce MVFs should be tailored by both geographic location and population sociodemographics. Such efforts could include culturally and geographically tailored public health education campaigns and outreach, subsidized car seats and safety devices for low-income populations, additional options for public and active transportation, and programs designed to encourage safe driving-or alternatives to driving-for younger and older drivers. Ultimately, all fatalities due to motor vehicle accidents should be considered avoidable deaths and every effort should be made to prevent them, especially in rural areas, where the overall mortality burden is higher. ${ }^{1}$ Achieving health equity for rural residents will require addressing motor vehicle usage and fatalities as an important social determinant of health.

\section{Acknowledgments}

This study was supported by the Federal Office of Rural Health Policy (FORHP), Health Resources and Services Administration (HRSA), and U.S. Department of Health and Human Services (HHS) under PHS Grant No. 5 U1CRH03717. The information, conclusions, and opinions expressed in this article are those of the authors and no endorsement by FORHP, HRSA, or HHS is intended or should be inferred.

\section{Author Disclosure Statement}

The authors have no conflicts of interest to disclose.

\section{References}

1. Garcia MC, Faul M, Massetti G, et al. Reducing Potentially Excess Deaths from the Five Leading Causes of Death in the Rural United States. MMWR Surveill Summ. 2017;66:1-7.

2. Pollack KM, Frattaroli S, Young JL, et al. Motor vehicle deaths among American Indian and Alaska Native Populations. Epidemiol Rev. 2012;34: 73-88.

3. Hedegaard H. QuickStats: age-Adjusted Rate of Motor Vehicle Traffic Deaths, by Urbanization of County of Residence-2005 and 2015. MMWR Morb Mortal Wkly Rep. 2017:66:567.

4. Mayrose J, Jehle D. An Analysis of Race and Demographic Factors among Motor vehicle fatalities. J Trauma. 2002;52:752-755.

5. Hamdan H. VCU Scholars Compass Racial/Ethnic Differences in Fatality Rates from Motor Vehicle Crashes: An Analysis from a Behavioral and Cultural Perspective.; 2013. Available at http://scholarscompass.vcu.edu/etd. Accessed June 13, 2017

6. Lee LK, Monuteaux MC, Burghardt LC, et al. Motor vehicle crash fatalities in states with primary versus secondary seat belt laws. Ann Intern Med. 2015;163:184.

7. Insurance Institute for Highway Safety Highway Loss Data Institute. Fatality Facts. General Statistics. Available at www.iihs.org/iihs/topics/t/ general-statistics/fatalityfacts/gender/2012. Published 2017 Accessed July 19, 2017.

8. Ferdinand AO, Menachemi N, Sen B, et al. Impact of texting laws on motor vehicular fatalities in the United States. Am J Public Health. 2014;104 1370-1377.

9. Grabowski DC, Campbell CM, Morrisey MA. Elderly licensure laws and motor vehicle fatalities. JAMA. 2004;291:2840. 
10. Zwerling C, Peek-Asa C, Whitten PS, et al. Fatal motor vehicle crashes in rural and urban areas: decomposing rates into contributing factors. Inj Prev. 2005;11:24-28.

11. Rakauskas ME, Ward NJ, Gerberich SG. Identification of differences between rural and urban safety cultures. Accid Anal Prev. 2009;41:931937.

12. Henning-Smith C, Evenson A, Kozhimannil K, et al. Geographic variation in transportation concerns and adaptations to travel-limiting health conditions in the United States. J Transp Health. 2018;8: $137-145$.
Cite this article as: Henning-Smith C, Kozhimannil KB (2018) RuralUrban Differences in Risk Factors for Motor Vehicle Fatalities, Health Equity 2:1, 260-263, DOI: 10.1089/heq.2018.0006

\section{Abbreviations Used \\ $\mathrm{MVF}=$ motor vehicle fatalities}

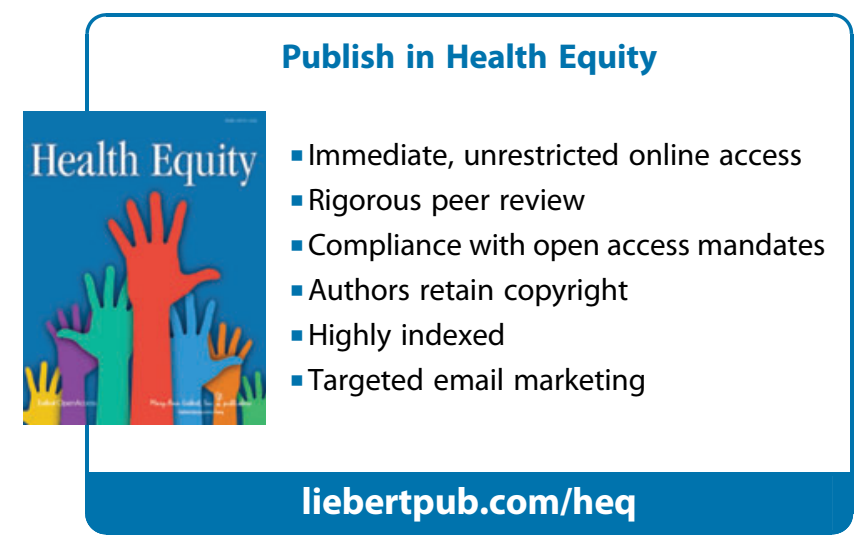

